\title{
Does the Nile reflect solar variability?
}

\author{
Alexander Ruzmaikin, Joan Feynman ${ }^{1}$ and Yuk Yung ${ }^{2}$ \\ ${ }^{1}$ Jet Propulsion Laboratory, California Institute of Tachnology, Pasadena, CA 91109, USA \\ emails: Alexander.Ruzmaikin@jpl.nasa.gov, Joan.Feynman@jpl.nasa.gov \\ ${ }^{2}$ Department of Geology and Planetary Sciences, California Institute of Technology, Pasadena, \\ CA 91103, USA \\ emal: yly@gps.caltech.edu
}

\begin{abstract}
Historical records of the Nile water level provide a unique opportunity to investigate the possibility that solar variability influences the Earth's climate. Particularly important are the annual records of the water level, which are uninterrupted for the years $622-1470$ A.D. These records are non-stationary, so that standard spectral analyses cannot adequately characterize them. Here the Empirical Mode Decomposition technique, which is designed to deal with nonstationary, nonlinear time series, becomes useful. It allows the identification of two characteristic time scales in the water level data that can be linked to solar variability: the 88 year period and a time scale of about 200 years. These time scales are also present in the concurrent aurora data. Auroras are driven by coronal mass ejections and the rate of auroras is an excellent proxy for solar variabiliy. Analysis of auroral data contemporaneous with the Nile data shows peaks at 88 years and about 200 years. This suggests a physical link between solar variability and the lowfrequency variations of the Nile water level. The link involves the influence of solar variability on the North Annual Mode of atmospheric variability and its North Atlantic and Indian Oceans patterns that affect rainfall over Eastren Equatorial Africa where the Nile originates.
\end{abstract}

Keywords. Sun: activity, Sun: solar-terrestrial relations, methods: statistical

\section{Introduction}

Knowledge of the water level of the Nile River was critically important for agriculture and the preservation of temples in Egypt throughout its history. Measurements of these levels have been carried out since the times of the pharaohs (Hurst 1952, Bell 1970). Shakespeare mentioned a Nilometer tower used in the measurement of water level: "Thus do they, sir. They take the flow o' the Nile by certain scales i' the pyramid; they know by the height, the lowness, or the mean, if dearth or foison follow. The higher Nilus swells the more it promises" (Antony and Cleopatra, Act II Scene VII). Annual records converted into metric units are available for 622-1470 A.D.Toussoun (1925). Such direct measurements are rare if not unique in long-term climatological studies, which usually rely on indirect measurements and proxies. We use these data (Figure 2) to investigate the possible influence of solar variability on the African climate. These Nile records have been previously examined by various spectral methods (Hameed 1984,DePutter Loutre \& Wansard 1998,Kondrashov, Feliks \& Ghil 2005). Specific periodicities, such as 7, 12, 19, $64,76,256$ years were reported. Solar influence on African climate on 80-120 years time scales was advocated by Yousef (2005). However the Nile time series are non-stationary in that no strict periodicities or oscillations at constant amplitudes are present. To better handle these data we apply the Empirical Mode Decomposition (EMD) technique, which is especially designed for analyses of non-stationary, nonlinear time series (Huang et al. 1998). The water of the Nile at Rawdah Island in Cairo, where the records were taken, is supplied predominantly by the Blue Nile (plus by the river Atbara) whose main source is Lake Tana in Ethiopia, and by the White Nile whose main source is Lake Victoria in 

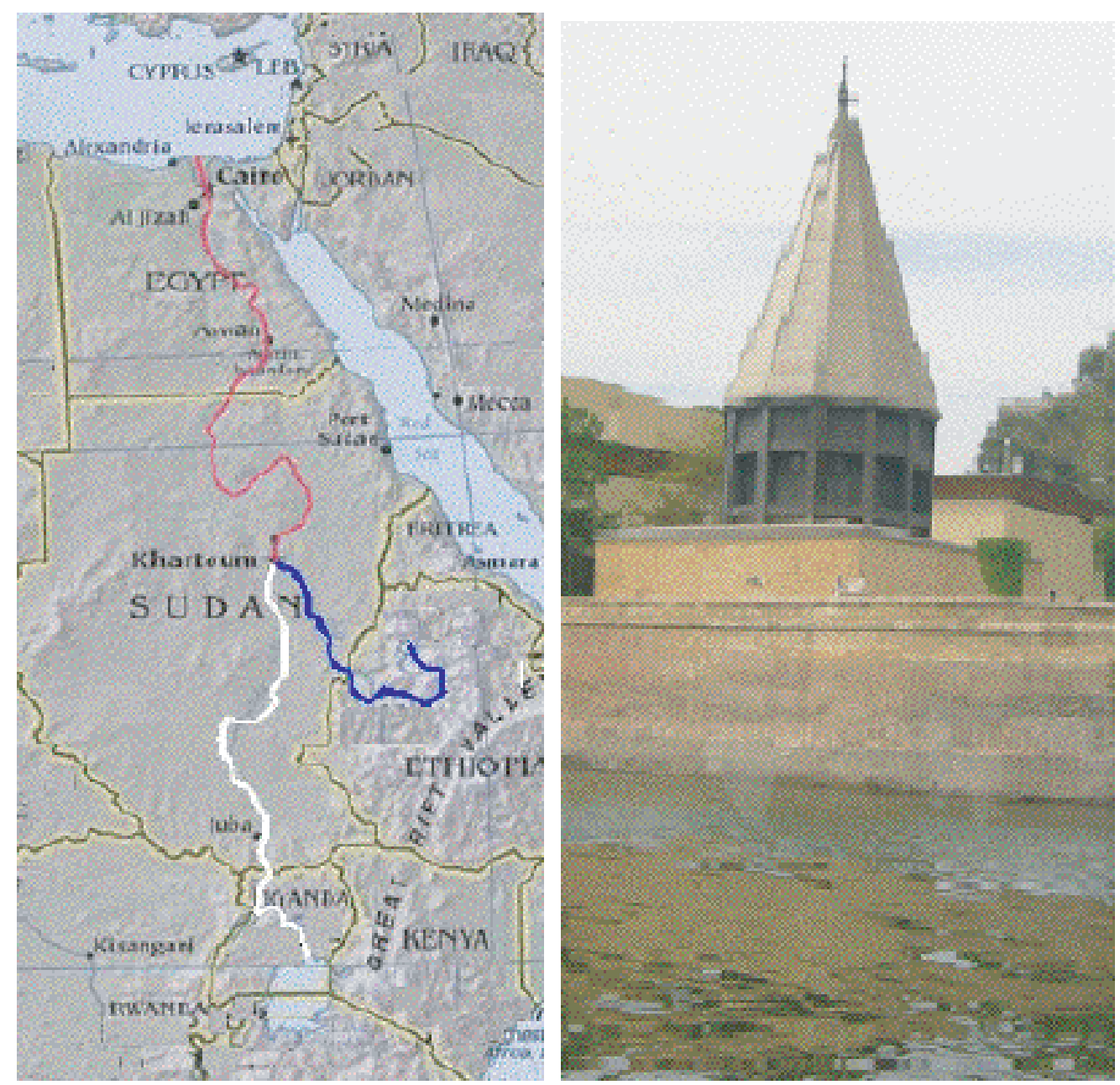

Figure 1. (left) The map of the Nile and its sources in East Equatorial Africa. (right) The Nilometer at the Rawdah Island in Cairo at the site where the meausrements with the old Nilometer were taken.

Eastern Equatorial Africa (Figure 1). The Blue Nile source accounts for about $90 \%$ of the levels in times of floods. These floods strongly reflect high-frequency variability of rainfall in Ethiopian highlands caused by localized convective storms and excursions of the Intertropical Convergence Zone (Nicholson 2000, Sene, Tate \& Farquharson 2001). In contrast, the White Nile is critically responsible (at about $83 \%$ ) for maintaining the Nile flow during the low-water levels in the dry (October-April) period (Hurst 1952). The low water levels show a rich low-frequency variability, which is rooted in the variability of Lake Victoria. However low-frequency variability is also seen in the high water levels. It has been suggested that the high-frequency peaks in the Nile records are linked to El Nino Southern Oscillation (ENSO) events (Rind 1996). Lower-frequency variations were suggested as possibly related to solar forcing (Hameed 1984, Loutre et al. 1992). 


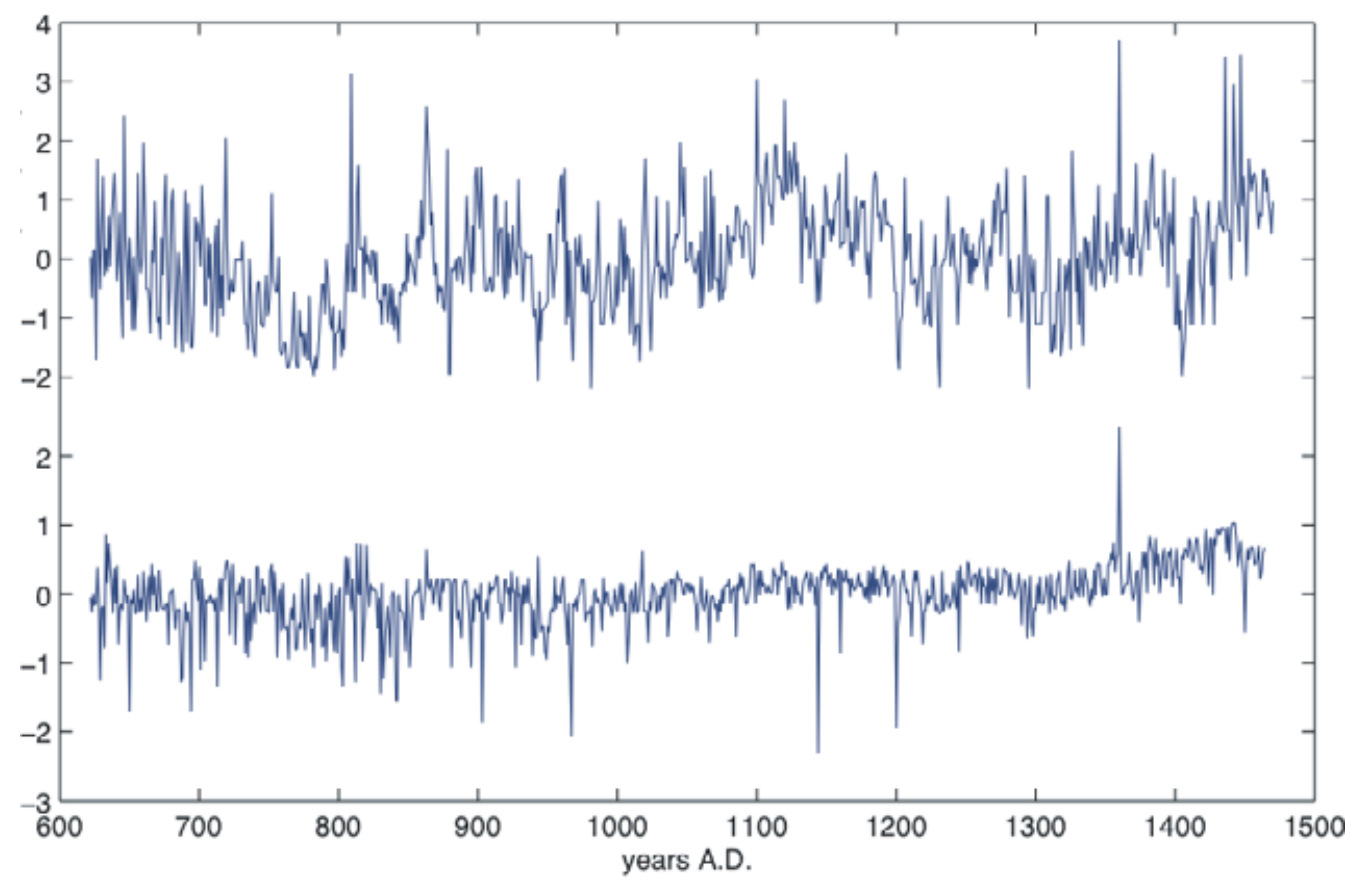

Figure 2. The low-water anomalies (upper graph) and flood (lower graph) records of the Nile River in $622-1470$. The anomalies are defined by subtracting mean values for the whole period.

\section{The Variability of the Nile Water Levels}

The EMD represents the data as the sum of a small number of orthogonal empirical modes that have time-variable amplitudes and instantaneous frequencies. Each mode has a symmetric envelope defined by the local maxima and minima so that its mean is zero everywhere. Its mean period can be determined by dividing the distance between the first and the last zero-crossing by $N-1$ where $N$ the number of zero-crossings(Huang et al. 1998). The instantaneous frequencies as functions of time are found for each mode with the help of the Hilbert transform. In comparison, the Fourier decomposition presents time series as a sum of harmonics with fixed frequencies and amplitudes. This usually requires many harmonics and works well when the frequencies are present all times, i.e. for stationary processes. The EMD is similar to the wavelet decomposition. However the wavelet decomposition employs a preset basis function (such as the Morlet wavelet). In contrast, the EMD basis is changing in time to adapt to the actual data variability. Figures 3, 4 show the modes and distributions of instantaneous frequencies for the Nile's low-water and high-water levels respectively. The peaks of the frequency distributions for the modes are in a general agreement with the frequencies found by earlier authors. For example, frequencies of the second modes (right upper panels) are peaked around $\left(7\right.$ year) ${ }^{-1}$ supporting a major result of Kondrashov, Feliks \& Ghil 2005. (To our judgment, however, the 7-year period does not quite fit the biblical story of droughts, because "seven years of drought" followed by "seven years of plenty" corresponds to a 14-year period.) These authors also found 64-year and 256-year variations, seen in 5th and 7th modes. Although the frequency distribution for mode 3 may be associated with the 11-year solar cycle it does not concentrate strongly around this period. The near 24-year variation in mode 4 may be associated with similar variation seen in the North Atlantic Oscillation (NAO) (Cook Darrigo \& Briffa 1998). The most interesting result is the 

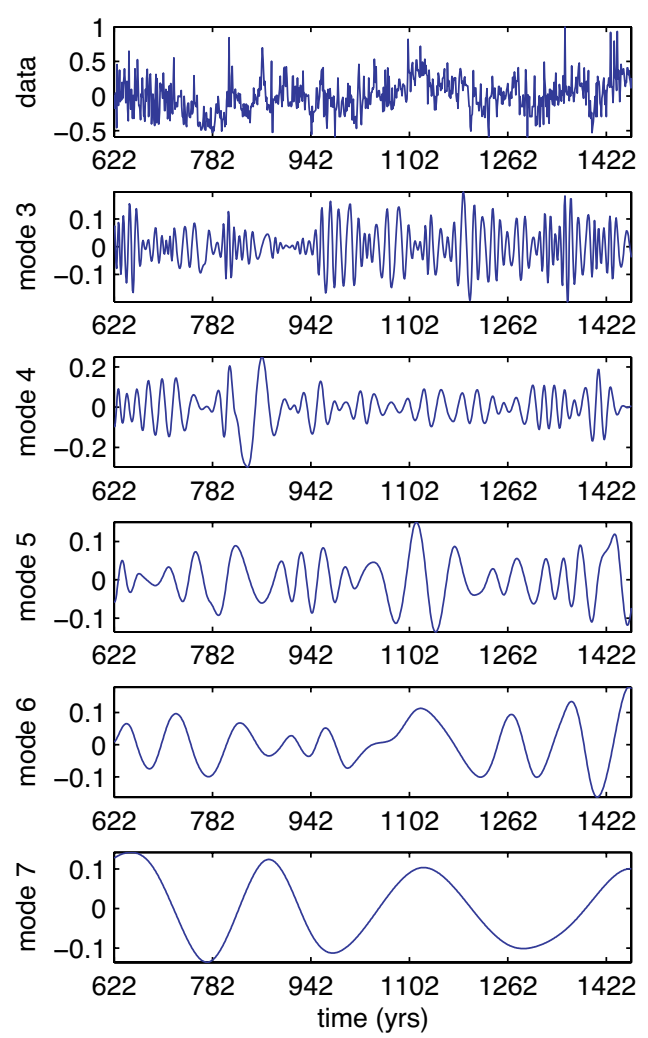
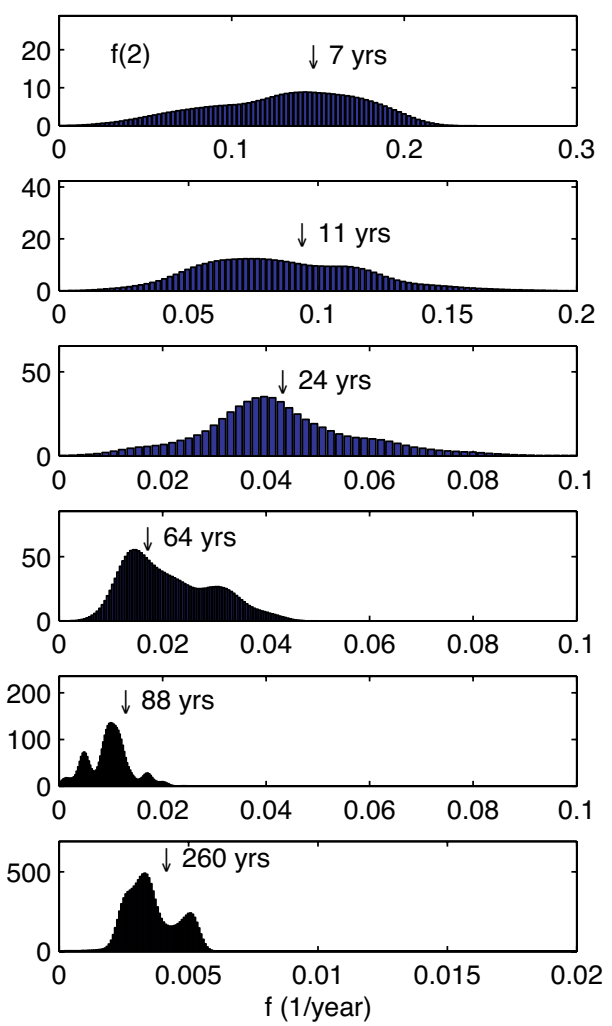

Figure 3. The EMD modes 3-7 and their instantaneous frequencies of the low-water record 622-1470 A.D. The frequency distribution for the second mode is shown in the upper right panel. The data were normalized to their maximum values.

dominance of the near 88-year periodicity in both records, as seen in the vertical scale of its histogram. This suggests a relation to solar variability, see below. The peak around 260 years in the low water level is possibly related to periodicities identified in the ${ }^{14} \mathrm{C}$ record and attributed to solar variability (Stuiver \& Brauzanias 1989). Statistical significance of the modes is evaluated in Ruzmaikin, Feynman \& Yung (2006). The 88-year and 200-year modes are statistically significant at $2 \sigma$ level against the white noise and at $1 \sigma$ level against the strongly correlated fractional noise (with the exception of the 400 year mode for the high waters).

\section{Concurrent Aurora record}

For almost 2000 years auroral appearances at mid latitudes in Europe and Asia were carefully recorded because of the belief that they portended important events such as droughts and deaths of kings. These records have been collected and evalutaed for accuracy (see Siscoe (1980) for a comprehensive review of sources of auroral data). Auroras are caused by very high speed solar wind diturbances produced in association with fast coronal mass ejections and major flares. The rate of auroras is strongly correlated with the sunspot number (correlation coefficient 0.85, see Feynman (1988)) and thus is an excellent proxy for solar variability. To evaluate a connection between the peak of the 88-year mode of the Nile records and the solar variability we applied the EMD to a record of the number of auroras reported per decade in the Northern Hemisphere in 620-1440 

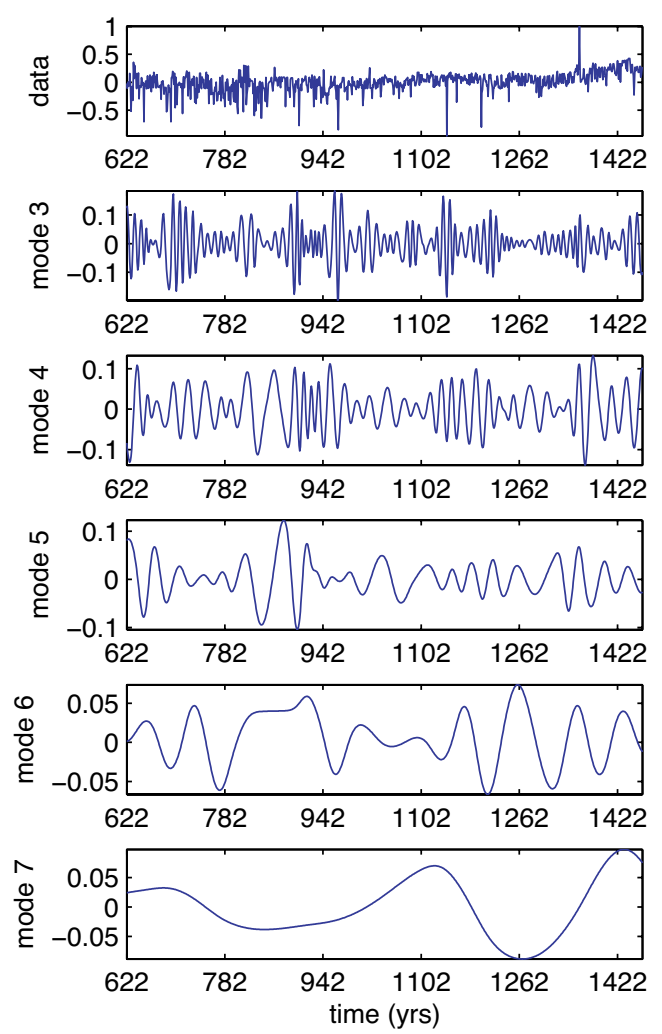
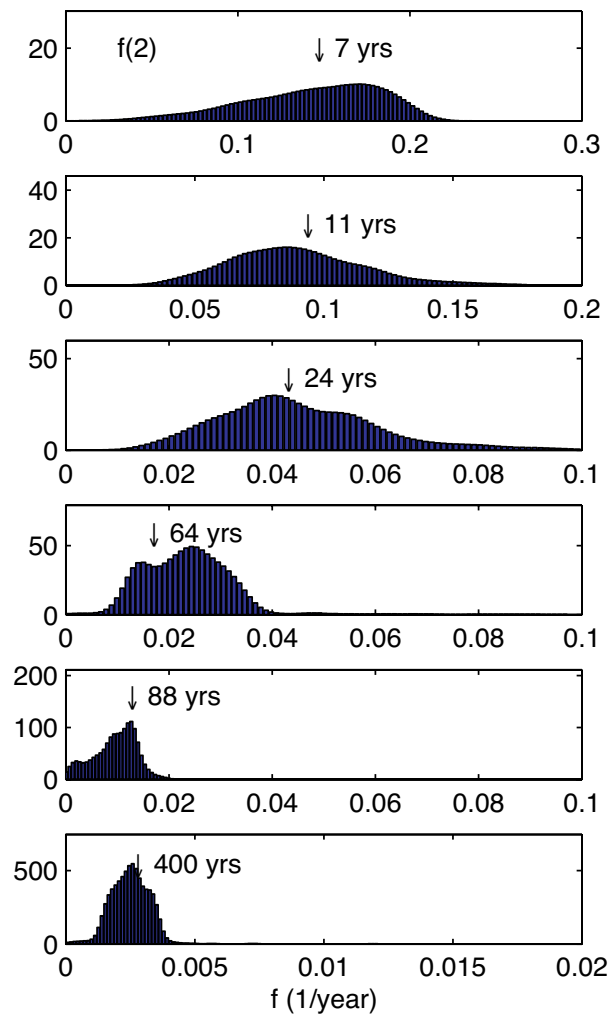

Figure 4. The same as Figure 3 for the high-water record.

$\mathrm{AD}$ as given by Feynman \& Fougere (1984). Figure 5 shows that the aurora's mode 2 has a frequency distribution peaked around 88-years.

\section{A possible link}

Both sources of the Nile (Lake Victoria and Lake Tana, see Figure 1) are fed by precipitation in Eastern Equatorial Africa. Here we focus our discussion on Lake Victoria. The low-water level of Nile in the extended winter (October-April) is largely determined by this lake, which drains $10 \%$ of its water into the White Nile (Sene, Tate \& Farquharson 2001). The water level of Lake Victoria is mostly controlled by rainfall and evaporation over the lake region. Thus the key question is "How does solar variability influence the rainfall and the evaporation conditions over the lake watershed?" Lacking rainfall data coincident with the Nile data used above, we can only discuss this problem by relying on more current data. Historically, an excellent correlation between the water level in the Lake Victoria and the 11-year sunspot cycle was first reported for the period 19021921 (Brooks 1923) but by 1927 the Lake-Sun correlation had weakened and then it reversed sign. However with the availability of high-resolution paleo records the 11-year cycle Lake-Sun connection has been resurrected. An accurate monthly record of the lake levels for the 20th century shows that a close correspondence between the lake levels and sunspot number re-appeared at about 1968 (Stager et al. 2005). Also a strong correlation between the atmospheric radiocarbon variations, caused by solar variability, and the levels of a small equatorial lake Naivasha (Kenya) was found (Verschuren, Laird \& Cumming 

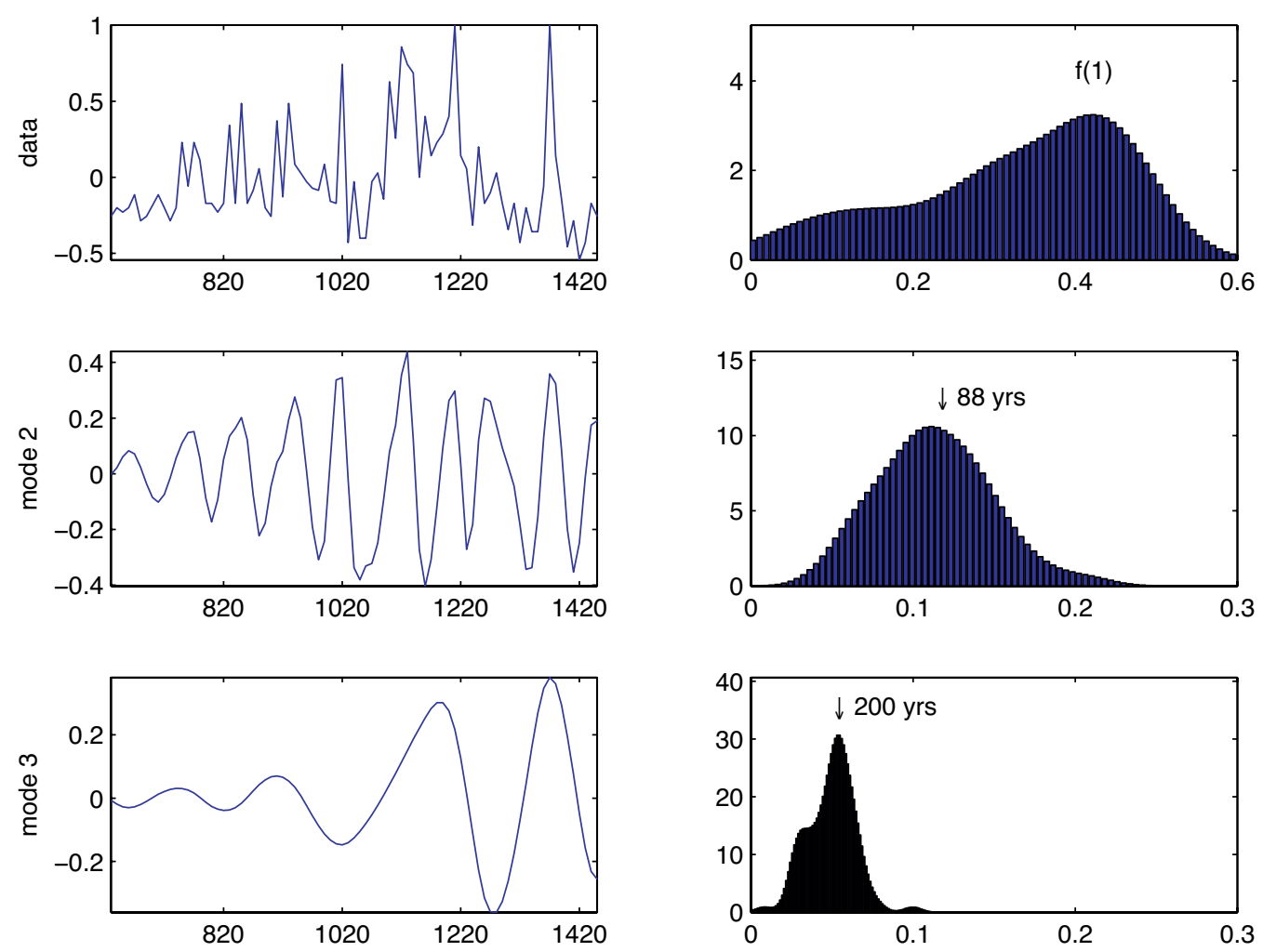

Figure 5. The EMD modes 3-7 and their instantaneous frequencies for auroras. For better comparison the data are normalized to its maximum value.

2000). The rainfall in Eastern Equatorial Africa shows interannual variability coherent throughout the region (Nicholson 2000). Much of this variability is accounted for by conditions during so called short rains in October- November-December (although stronger rains occur in March-April-May). The most prominent variability has a time scale of 56 years typical for the ENSO. The study of the Indian rainfall over 120 years showed that the greater rainfall is associated with greater solar activity (Bhattacharyya \& Narasimha 2005). It has been argued (Black, Slingo \& Sperber 2003) that extreme short rains are associated with the large-scale sea-surface temperature (SST) gradient across the Indian Ocean. The positive gradient weakens the westerly wind that normally transports moisture away from the African continent toward the Indian Ocean. Climatological mean value of the gradient is near zero in times of short rains allowing the Atlantic El Nińo to affect this weak SST gradient. This can open a door for solar variability influence in two possible ways: (1) The quasi-random ENSO variations may amplify the effect of the solar cycle through stochastic resonance (Ruzmaikin 1999); (2) The large-scale SST gradient in the Indian Ocean can be affected by the major anomalous pattern of the Atlantic Ocean, the North Atlantic Oscillation (NAO) (Hurrel 1996). The associated SST anomalies show a meridional tripole pattern: cool north of $55 \mathrm{deg} \mathrm{N}$, warm in $20-55 \mathrm{degN}$ band, and cool south of $20 \mathrm{deg} \mathrm{N}$ (positive phase of the NAO). The sign of this anomaly is opposite in the negative phase of the NAO (Seager et al. 2000). During the positive (negative) phase of the NAO an anomalous upper tropospheric descending (ascending) airflow prevails in Equatorial Eastern Africa (Wang (2002)). This airflow corresponds to drier (wetter) conditions over Lake Victoria and Lake Tana. A solar influence on the NAO in 1900-1999 
was reported by Kodera (2003). He found that during low solar activity the NAO signal is confined to the Atlantic sector, while during the high solar activity the NAO-related anomalies extend over the whole Northern Hemisphere. The relationship between the NAO and solar variability can be understood by taking into account that the NAO is a surface manifestation of the North Annular Mode (NAM) that extends from sea level to the top of the stratosphere (Thompson \& Wallace 1998). By analyzing the atmospheric geopotential heights in 1958-1997 Ruzmaikin \& Feynman (2002) showed that the NAM is statistically significantly affected by the solar variability. Recently Hameed \& Lee (2005), who used the same data, reported that a greater fraction of stratospheric perturbations penetrate to the Earth's surface during solar maximum conditions than during solar minimum conditions. Strong variations of the solar UV flux in the stratosphere modulate the ozone and temperature gradients influencing the interaction of the mean zonal wind and planetary waves that generate the NAM (Lean \& Rind (1998), Limpasuvan \& Hartmann 2000). These studies were limited to the solar cycle time scale. However, our analysis of the Nile data (Figures 3,4) does not show a clear solar cycle; instead twe see a wide spread of frequencies around 11 years. It is particularly puzzling since solar cycle is seen in Lake Victoria (Stager et al. 2005), which is a source of the White Nile. A possible explanation can be inferred from water balance studies (Nicholson 2000, Sene, Tate \& Farquharson 2001). The White Nile starts as an outflow from Lake Victoria and then is affected by a chain of smaller lakes and swamps, the largest of which is the Sudd swamp. The lake level is balanced by precipitation, minus evaporation, plus contributions of tributary inflows, minus the White Nile outflow. This outflow is a nonlinear function of the lake water level that in turn depends on immediate rainfall and a delayed runoff from the watershed area. The down the river chain of lakes and swamps induces damping and time delays for the flow. For example, if the lake level suddenly rises, due to a heavy rainfall, and then the net basin supply returns to its previous value, the lake level decreases exponentially to its equilibrium state but the White Nile behaves differently. Numerical modeling (Sene, Tate \& Farquharson 2001) showed that if the lake level were increased by $1 \mathrm{~m}$, the characteristic (half life) time constant for the White Nile outflow restoration would be about 8 years. Note that there is a second peak near about 8 years in the frequency distribution for this mode (Figure 2), and no such peak is seen in the frequency distribution for this mode for the high-water levels (Figure 4). That is why the solar cyle is clearly seen in Lake Victoria than in the White Nile. The damping effects are not important on time scales longer than 11-year cycle, such as the 88-year scale. Solar variability influence on these scales is also not damped by the ocean. It has been shown that the reconstructed sensitivity of the sea level temperature to longterm solar forcing in the Northern Hemisphere is in agreement with empirical temperature patterns corresponding to changes of the NAM (Ruzmaikin et al. 2004). This implies that long-term solar variability affects the atmosphere predominantly through the NAM and hence the ocean through the NAO.

\section{Acknowledgements}

We are grateful to D. Percival for providing the Nile data and N. Huang for his advices on the EMD. We thank the meeting participants \& students for helpful questions. This research was carried out in part at the Jet Propulsion Laboratory, California Institute of Technology, under a contract with the National Aeronautics and Space Administration.

\section{References}

Bell, B. 1970, The Oldest Records of the Nile Floods, Geographical Journal 136, 569 
Bhattacharyya, S. and R. Narasimha 2005, Geophys. Res. Lett. 32, L05813, doi:10.1029/2004GRL021044

Black, E., Slingo, J. \& Sperber, K. R. 2003, Mon. Weather Rev. 131, 74

Brooks, C. E. P. 1923, Geophys. Memoirs, London 2, 334

Cook E. R., Darrigo, R. D. \& Briffa, K. R. 1998, The Holocene 8(1), 9

De Putter, T., Loutre, M. F. \& Wansard, G. 1998, Geophys. Res. Lett. 25, 3193

Feynman, J. P. 1988 in: Stephenson F. R. \& Wolfendale, A. W. (eds.), Secular Solar and Geomagnetic Variations in the last 10000 years (Kluwer Acad. Press)

Feynman, J. P. \& Fougere, F. 1984, J. Geophys. Res. 89, 3023

Hameed, S. 1984, Geophys. Res. Lett. 1, 843

Hameed, S. \& Lee, J. N. 2005, Geophys. Res. Lett., 32, doi: 10.1029/2005GL024393

Hurrel, J. M. 1996, Geophys. Res. Lett. 23, 665

Hurst, H. E. 1952, The Nile, 326 pp., Constable, London

Huang, N. E., Shen, Z., Long, S. R., Wu, M. C., Shih, H. H., Zheng, Q., Yen, N.-C., Tung, C. C. \& Liu,H. H. 1998, Proc. R. Soc. Lond. A 454, 903

Kodera, K. 2003, Geophys. Res. Lett. 30, doi:10.1029/2002GL016584

Kondrashov, D., Feliks, Y. \& Ghil, M. 2005, Geophys. Res. Lett. 32, L10702, doi:10.1029/2004GL022156

Limpasuvan, V. \& Hartmann, D. L. 2000, J. of Clim. 13, 4414

Loutre, M.-F., Berger, A., Bretagon, P. \& Blanc, P.-L. 1992, J. Clim. Dyn. 7, 181

Lean, J. \& Rind, D. 1998, J. Climate 11, 3069

Nicholson, S. E. 2000, Global Planet. Change 26, 137

Rind, D. 1996, in: Jones, P. D., Bradley, R. S. \& Jouzel, J. (eds.), Climate variations and forcing mechanisms of the last 2000 years, (Springer) p. 563

Ruzmaikin, A. 1999, Geophys. Res. Lett. 26, 2255

Ruzmaikin, A. \& Feynman, J. 2002, J. Geophys. Res. 107, D14, 10.1029/2001JD001239

Ruzmaikin, A., Feynman, J., Jiang, X., Noone, D., Waple, A. \& Yung, Y. 2004, Geophys. Res. Lett. 31, L12201, doi:10.1029/2004GL0019955

Ruzmaikin, A., Feynman, J. \& Yung, Y. 2006, J. Geophys. Res. submitted

Seager, R., Kushnir, Y., Visbeck, M., Naik, N., Miller, J., Krahmann, G. \& Cullen, H. 2000, J. Climate 13, 2845

Sene, K. J., Tate, E. L. \& Farquharson, F. A. K. 2001, Climate Change 50, 177

Siscoe, G. L. 1980, Rev. Geophys. Space Sci. 18, 647

Stager, J. C., Ryves, D., Cumming, B., Meeker, L. D. \& Beer, J. 2005, J. Paleolimnol 33, 243

Stuiver, M. \& Brauzanias, T. F. 1989, Nature, 338, 405

Toussoun, J. D. 1925, Mem. Inst. Egipte 18, 366

Thompson, D. W. J. \& Wallace, J. M. 1998, J. Geophys. Res. Lett. 25, 1297

Verschuren, D., Laird, K. R. \& Cumming, B. F. 2000, Nature 403, 410

Wang, C. 2002, J. Climate 15, 1516

Yousef, S. 2005, in: Climate Variability Over Africa, Symp. (Alexandria, May 2005) 